\title{
Solid-phase microextraction for determining twelve orange flavour compounds in a model beverage emulsion
}

\begin{abstract}
Solid-phase microextraction (SPME) coupled to gas chromatography has been applied for the headspace analysis (HS) of 12 target $1 / 2$ avour compounds in a model orange beverage emulsion. The main volatile $1 / 2$ avour compounds studied were: acetal- dehyde, ethyl acetate, $\alpha$-pinene, ethyl butyrate, $\beta$-pinene, myrcene, limonene, $\gamma$-terpinene, octanal, decanal, linalool and citral (neral plus geranial). After screening the $1 / 4$ bre type, the effect of other HS-SPME variables such as adsorption temperature $\left(25-55^{\circ} \mathrm{C}\right)$, extraction time $(10-40 \mathrm{~min})$, sample concentration $(1-100 \% \mathrm{w} / \mathrm{w})$, sample amount $(5-10 \mathrm{~g})$ and salt amount $(0-30 \% \mathrm{w} / \mathrm{w})$ were determined using a two-level fractional factorial design (25-2) that was expanded further to a central composite design. It was found that an extraction process using a carboxenpolydimethylsiloxane $1 / 4$ bre coating at $15^{\circ} \mathrm{C}$ for $50 \mathrm{~min}$ with $5 \mathrm{~g}$ of diluted emulsion $1 \%(\mathrm{w} / \mathrm{w})$ and $30 \%(\mathrm{w} / \mathrm{w})$ of sodium chloride under stirring mode resulted in the highest HS extraction ef1/4ciency. For all volatile $1 / 2$ avour compounds, the linearity values were accurate in the concentration ranges studied ( 2 >0.97). Average recoveries that ranged from 90.3 to $124.8 \%$ showed a good accuracy for the optimised method. The relative standard deviation for six replicates of all volatile $1 / 2$ avour compounds was found to be less than $15 \%$. For all volatile $1 / 2$ avour compounds, the limit of detection ranged from 0.20 to $1.69 \mathrm{mg} / \mathrm{L}$.
\end{abstract}

Keyword: Solid-phase microextraction; Headspace analysis; Orange beverage emulsion; Fractional factorial design; Central composite design; Extraction efficiency 